\title{
A Cooperativa dos Agricultores do Assentamento Itamarati II: Mediação entre o Estado e os Produtores
}

http://dx.doi.org/10.21527/2237-6453.2018.45.336-353

Recebido em: $14 / 10 / 2016$

Aceito em: 12/06/2018

Marco Aurélio Perroni Pires ${ }^{1}$, Sandino Hoff ${ }^{2}$

\begin{abstract}
RESUMO
O presente artigo teve o objetivo de analisar a mediação exercida na produção agrícola e na comercialização de mercadorias pela Cooperativa dos Produtores do Assentamento Itamarati II - Cooperai de Ponta Porã, MS, Brasil - 2013 a 2017. Os instrumentos utilizados na coleta de dados constituíram-se de entrevistas semiestruturadas com as famílias cooperadas e com pessoas ligadas diretamente às instituições participantes da produção e comercialização dos assentados; de documentos e registros encontrados na Companhia Nacional de Abastecimento (Conab) de Campo Grande; na Secretaria Municipal de Educação; no escritório do Banco de Alimentos de Ponta Porã, Programa de Aquisição Alimentar (BAP); em órgãos como Pronaf e na Cooperai. Constatou-se que o número de associados da Cooperativa é reduzido. Utilizando os programas do governo, a Cooperai fomentou a produtividade e a renda dos membros cobriu apenas a sobrevivência das famílias. Os resultados apontaram para reduzido acesso de cooperados ao financiamento e às tecnologias de produção; para a proteção econômica do governo na aquisição dos gêneros alimentícios diretamente da agricultura familiar. A positiva função social exercida pela Cooperai esteve dependente das instituições governamentais.
\end{abstract}

Palavras-chave: Políticas públicas. Desenvolvimento familiar. Órgãos governamentais.

\section{THE COOPERATIVE OF RURAL WORKERS OF SETTLEMENT ITAMARATI II: MEDIATION BETWEEN THE STATE AND THE PRODUCERS}

\begin{abstract}
The article aimed to analyze the mediation exercised in agricultural production and marketing of goods by the Cooperative of Producers Settlement Itamarati II - co-operai in Ponta Porã, MS, Brazil - 2013 to 2017. The instruments used for data collection consisted of semi-structured interviews with cooperative families and persons connected directly to institutions participating in the production and marketing of the settlers; documents and records found in the National Supply Company (Conab) of Campo Grande, the Municipal Department of Education, the Office of Ponta Porã Food Bank, Food Acquisition Program (BAP) in organs such as PRONAF and cooperai. It was found that the number of members of the cooperative is reduced. Using government programs, to co-operate fostered productivity and income of members covered only the survival of families. The results showed reduced access to financing and production technologies; for the economic protection of the government in the purchase of foodstuff, directly from family farmers. The positive social function performed by cooperai was dependent on government institutions.
\end{abstract}

Keywords: Public policies. Family development. Governmental institutions.

\footnotetext{
${ }^{1}$ Doutor em Meio Ambiente e Desenvolvimento Regional pela Uniderp/Kroton. Professor da Universidade Estadual do Mato Grosso do Sul. marcoaureliodrtd@gmail.com

2 Doutor em Filosofia e História da Educação pela Pontifícia Universidade Católica de São Paulo. Professor do Doutorado em Meio Ambiente e Desenvolvivmento Regional da Universidade Anhanguera-Uniderp.sandino.hoff@terra.com.br
} 
Os assentamentos de agricultores fazem parte da Reforma Agrária, um programa do governo brasileiro que distribui terras a famílias agrícolas. Apesar das políticas de financiamentos governamentais e a despeito de uma quantia inicial que cada assentado recebe exclusivamente para despesas de construção da moradia, as pesquisas sobre produção de assentamentos em Mato Grosso do Sul revelam reduzida produtividade. A essa conclusão chegaram Lima et al (2016), Oliveira, Souza e Mercante (2017) e Toniasso et al (2008), ao mensurar a sustentabilidade dos assentados.

Leite, Heredia e Medeiros (2004) e seu grupo de pesquisa realizaram uma análise geral de assentamentos, localizados em diversas regiões do Brasil e apontaram "para uma situação bastante deficiente". A precariedade do meio rural brasileiro e, em especial, das "áreas de predomínio de agricultores familiares pauperizados" não significa, porém, conforme eles, que "a criação dos assentamentos não possa provocar algumas alterações nesse panorama" (2004). Encontram-se, porém, pesquisas realizadas em assentamentos que demonstraram experiências de sustentabilidade, conforme se constatou no levantamento bibliográfico realizado para este trabalho.

Os assentados da Reforma Agrária, em geral, têm origens diversas, conforme áreas selecionadas, o que indica também categorias sociais com diferenças de inserção no processo produtivo: produtores rurais que perderam a terra, antigos acampados, agricultores expulsos por desapropriações ou por rearranjos fundiários executados pelos donos de grandes extensões de terras. No Itamarati II estão assentados, em sua maioria, trabalhadores que perderam suas terras ou foram demitidos das fazendas; quase todos passaram períodos em acampamentos (AGÊNCIA..., 2015).

O assentamento Itamarati II foi catalogado no Incra sob a responsabilidade da Agência de Desenvolvimento Agrário e Extensão Rural - Agraer. Localiza-se na BR 164, a 350 quilômetros da cidade de Campo Grande e a 50 quilômetros de Ponta Porã. Ocupando uma área de 25.000 ha, foi criado com a insolvência da Fazenda Itamarati. Apesar do destaque nacional desta fazenda na categoria de produção de commodities, as dívidas foram se multiplicando e parte do empreendimento foi entregue ao banco como garantia hipotecária. O governo comprou as terras e pagou ao proprietário 165 milhões de reais e ao banco 27,5 milhões. De posse da fazenda, o Estado deu-lhe uma função social.

Ao tomar posse de seus lotes, os assentados passaram a se deparar com um conjunto bastante amplo de atores, de instituições governamentais (Incra, prefeituras, secretarias, organismos de assistência técnica, Instituto Brasileiro do Meio Ambiente e dos Recursos Naturais Renováveis - Ibama, Mapa), de Organizações Não Governamentais e de um corpo de apoio e assessoria às demandas de trabalhadores rurais e à elaboração de projetos específicos. Em seus lotes, algumas famílias buscaram um instrumento que Ihes fornecesse condições de cultivar produtivamente o solo e os capacitasse a superar a precariedade da produção rural. A cooperativa começou a fazer parte de seu mundo social.

A Cooperativa dos Produtores do Assentamento Itamarati II - Cooperai - é o tema deste estudo. Atribuiu-se às atividades da Cooperativa o papel de mediação entre o Estado e a comercialização dos produtos dos cooperados. Justificou-se o objeto de investigação porque ela desempenhou o papel de intermediar todas as atividades dos órgãos 
governamentais com os produtores rurais do assentamento. O objetivo foi analisar a Cooperai de Ponta Porã, MS, em sua função de mediação ou de instrumento facilitador no cultivo agrícola e no destino das mercadorias produzidas pelas famílias cooperadas.

\section{REFERENCIAL TEÓRICO}

Os estudos, realizados por pesquisadores, indicam situações e problemas dos assentados, auxiliados ou não por cooperativas. As pesquisas locais e pontuais foram elaboradas para se obter um entendimento geral do desenvolvimento das famílias assentadas. Evidenciaram o lado positivo e o lado negativo das tentativas de produção agrícola realizadas pelo trabalho familiar.

Bellé, Alves e Souza analisaram o desenvolvimento regional decorrente do Assentamento Itamarati, como um todo, e apresentaram características importantes extraídas das entrevistas que realizaram: "Um dos objetivos dos movimentos sociais rurais é reocupar e reorganizar a exploração da terra, com o intuito de elevar o assentado ao exercício dos direitos de cidadania" (2013). Acentuaram a importância da luta dos assentados: "Tais movimentos lutam pela terra como expressão do trabalho e da vida, em contraposição ao movimento de expropriação determinado pelo capital". Concluíram, também, com um problema: "A contradição, porém, é a de que, quando alcançam essa conquista, os assentados inserem-se na produção na condição de detentores de capital" (BELLÉ; ALVES; SOUZA, 2013).

O trabalho de pesquisa extensiva que fez Terra (2009) possibilitou-Ihe tirar algumas conclusões, entre elas as difíceis condições das famílias:

Se as condições das famílias do Assentamento Itamarati são difíceis, as das assentadas no Itamarati II são muito piores, pois apesar de possuir uma área com dimensões semelhantes às do primeiro (aproximadamente 25.000ha) e um número menor de unidades de irrigação (apenas 27 pivôs), envolveu uma quantidade maior de famílias (1.692), agrupadas em cinco organizações de trabalhadores, e está envolvido em um processo de implantação que vem se arrastando desde 2004 (p. 304-305).

Borges (2018) considera que "a produção cooperativa em larga escala, voltada para a industrialização e o mercado externo, perde espaço para o incentivo à produção agroecológica, baseada na diversificação da produção e utilização de recursos internos e valorização do conhecimento tradicional (camponês)". O autor coloca-se na luta contra o agronegócio que degrada, exclui, "concentra as terras e destrói o meio ambiente" e apresenta como contraponto "a agroecologia e seus princípios, totalmente diversos ao paradigma agrícola agroexportador" (BORGES, 2018).

Marconi e Santos (2016) analisam o modelo de cooperativismo adotado pela Cooperativa de Comercialização e Reforma Agrária União Camponesa - Copran - e a definem como "cooperativa de compras e vendas proposto por Singer: industrialização dos produtos, comercialização dos produtos, projetos de financiamento e aluguel de máquinas agrícolas" (MARCONI; SANTOS, 2016). Concluem que existem avanços, " como a melhor remuneração pelo produto, a centralização do recebimento e armazenamento do leite, através da organização dos Círculos Curtos de Proximidade (CCP) e principalmente as parcerias da cooperativa com órgãos públicos, privados e entidades parceiras da agricultura familiar" (2016). 
Os aportes teóricos, fornecidos pelo Núcleo de Estudos Agrários e Desenvolvimento Rural - Nead - em 2004, compuseram um quadro abrangente sobre os assentamentos brasileiros e revelaram a importância do Estado e das cooperativas na agricultura familiar. As pesquisas em assentamentos de Mato Grosso do Sul realizadas por Toniasso et al. (2008) e Lima et al. (2016) e com os mesmos resultados de Oliveira, Souza e Mercante (2017), concluíram que os produtores dos assentamentos alcançaram apenas o mínimo de sustentabilidade. Os resultados do Nead estão, assim, aptos a auxiliar este estudo sobre a situação econômica dos produtores rurais do Assentamento Itamarati II. As citações extraídas destes e de outros autores são válidas para a pesquisa, porque subsiste a sociedade capitalista de produção com suas leis de mercado e subsistem os problemas sociais e econômicos das famílias rurais, cooperadas ou não.

Para se entender a função social, mediada pela Cooperai no interior do Assentamento, é necessário apreender os verdadeiros motivos que levaram o Estado a patrociná-la e porque a agroindústria não se interessa pelo produto gerado nos assentamentos. A investigação coloca a função social no terreno da produção material, porque a cooperativa deve dar conta da produção e da comercialização dos produtos. O motivo de sua atuação é fazer com que o agricultor se aproprie do valor excedente que gerou na lavoura, mas "esta apropriação, na forma-dinheiro, só se torna possível depois que as mercadorias são realizadas, isto é, quando o valor abandona a forma mercadoria e adquire a forma do equivalente universal: o dinheiro" (AUED, 1981, p. 21), o que ocorre na distribuição e no consumo.

Geralmente ocorrem condições estruturais e conjunturais que provocam interrupções na produção de valor. No caso das atividades da cooperativa na produção e na comercialização da lavoura tem-se a dificuldade de produzir valor numa pequena produção agrícola. Por essa razão, o Estado exerce a função de atuar como força reguladora e como aporte de recursos, criando mecanismos de financiamento para assegurar a sobrevivência dos agricultores assentados.

\section{As Razões de Ser do Mercado}

Buscou-se apreender as verdadeiras razões de ser que levam o mercado a exigir uma produção condizente a seus interesses. Para tanto foi preciso verificar o agronegócio, definido por Borges (2018) como "a produção cooperativa em larga escala, voltada para a industrialização e mercado externo". Na opinião deste autor, o agronegócio incorre no erro de "degradar, excluir, concentrar as terras e destruir o meio ambiente" e se posiciona contra a função social da produção agrícola. A conquista da terra e o sucesso na produção dos assentados, para ele, apresentam um contraponto: “Agroecologia e seus princípios (são) totalmente diversos ao paradigma agrícola agroexportador, baseado na diversificação da produção e utilização de recursos internos e valorização do conhecimento tradicional" (2018).

Tem-se, assim, a produção para a agroindústria, de um lado, e a produção dos assentados, de outro. Ambas necessitam ser postas em investigação, a fim de se verificar como funcionam e apreender os verdadeiros moventes que levam às razões de ser de ambas. 
A primeira razão refere-se à agroindústria afirmar que as trocas das mercadorias não levam na fronte sua determinação de valor-trabalho. Isso significa que a divisão entre trabalho pago e não pago não é visível na produção capitalista, embora tenha sido transparente nos modos de produção anteriores. Assim, no modo de produção primitivo, o trabalho coletivo era totalmente translúcido; na escravidão era visível o trabalho do escravo em troca de alimento, vestuário e abrigo; o trabalho dividido em jornadas de três dias para o senhor feudal em pagamento da renda da terra era perceptível (MARX, $1980,1,2$, p. 622). O valor-trabalho na sociedade capitalista permanece oculto. O ponto de vista do capitalista é que ele cumpre a lei e paga o trabalho despendido pelo trabaIhador, mas oculta a divisão do trabalho em pago e não pago (mais-valia). Dessa forma, o salário não deixa visível que a força de trabalho é uma mercadoria, que se compra e se vende abaixo do preço.

A segunda razão de ser é a posição do assentado. Ele vende seu produto, após ter despendido trabalho para realizá-lo. A sua atividade não estava submetida diretamente ao assalariamento, isto é, ao comando do capitalista e também não forneceu seu produto a algum empresário. O não assalariamento direto, no entanto, não retira do trabaIho familiar o caráter capitalista.

A terceira razão de ser refere-se ao capital que só atua com o produtor rural quando este, direta ou indiretamente, submete-se às normas da produção, à precificação do contrato, ao uso de sementes, pesticidas e de adubação, por ele prescritos ou indicados. O produtor rural independente dispõe a sua força de trabalho, mas não a fornece a ninguém, o que não agrada ao capitalista. O ponto de vista do empresário são interesses práticos: comprar o uso da força de trabalho o menos caro possível e de lucrar o mais possível com o trabalho expropriado e pagar o salário ao trabalhador, considerado como o pagamento do trabalho despendido e não o valor da força de trabalho. Além disso, para o capitalista, a agroindústria é o único comprador dos produtos agrícolas.

A função social do assentado em salvar a pequena propriedade e impedir a quimificação da lavoura e a concentração das propriedades fundiárias fica com poucas opções diante do capital que opera com alta tecnologia e com capital financeiro à disposição. É o que indica a quarta razão de ser e se refere à posição ideológica dos assentados.

A última razão de ser é a do mercado. Demonstra que a produção material na atualidade brasileira, em forma de cooperativas modernas e do agronegócio, ultrapassou a fase da concorrência, operando em oligopólios. A substituição da livre concorrência pelos oligopólios é, juntamente com o capital financeiro, traço fundamental da fase imperialista do capitalismo. A produção agrícola dos cooperados do Itamarati II, mediada pela Cooperai, coloca-se fora da concorrência, no protecionismo do Estado.

\section{METODOLOGIA}

As famílias foram assentadas no Itamarati II pelo Movimento dos Trabalhadores Rurais Sem Terra (MST), constituído por 320 famílias; pela Central Única dos Trabalhadores (CUT), com 280 famílias; pela Federação dos Trabalhadores na Agricultura (Fetagri), com 395 famílias, e pela Associação dos Moradores e Funcionários da Fazenda Itamarati (Amffi), com 150 famílias (TERRA, 2009, p. 155). A área localiza-se a 45 km da sede do município de Ponta Porã, Mato Grosso do Sul, e a $21 \mathrm{~km}$ da faixa de fronteira 
com o Paraguai (TERRA, 2009, p. 149). Terra (2009, p. 131) ressalta as distintas bandeiras político-ideológicas e organizadas por diferentes e divergentes entidades de luta pela terra, no caso, a CUT, a Fetagri e o MST.

A coleta de dados empíricos, utilizados para atender ao objetivo da pesquisa, foi feita com levantamento da produção e da comercialização, que revelou a mediação exercida pela Cooperai entre produtor e comprador; entrevistas com roteiros semiestruturados realizadas com assentados e agentes das instituições governamentais, acionadas na comercialização dos produtos; dados coletados na Companhia Nacional de Abastecimento - Conab de Campo Grande, no Programa de Aquisição Alimentar - PAA, no Programa Nacional de Alimentação Escolar - Pnae, no Programa Nacional de Fortalecimento da Agricultura Familiar - Pronaf, na Secretaria Municipal da Educação de Ponta Porã e na Cooperai. O conjunto de dados coletados revelou a mediação exercida pela Cooperai entre produtor e comprador, intermediando todas as instituições participantes no processo.

A análise das ações da Cooperativa no interior do Assentamento foi feita pela categoria mediação, entendida pela forma como é utilizada pelos clássicos, a exemplo de Saviani (1983), Lukacs (2016) e outros. Saviani (1983, p. 120), referindo-se à competência técnica e ao compromisso político dos professores, indica como se utiliza a categoria mediação. "A competência técnica é mediação, isto quer dizer que ela está entre, no meio, no interior do compromisso político. Ela é mediação, ou seja, é também (não somente) por seu intermédio que se realiza o compromisso político". A categoria mediação é a melhor forma de se evitar uma análise de causa/efeito na pesquisa qualitativa. A categoria manifesta que é também, não somente, por intermédio da cooperativa, que se realizaram as atividades agrárias no Assentamento e o desenvolvimento das famílias. Assim, a função social dos assentados cumpre-se pela mediação da Cooperativa, ou seja, a Cooperai foi uma das formas por meio das quais se explicitou a geração e a comercialização dos produtos agrários. Indica a importância e a necessidade da Cooperativa e, ao mesmo tempo, a sua insuficiência.

\section{RESULTADOS}

Os assentados têm um comprometimento de sua função social, emerso de sua experiência e de sua formação de luta pela terra. É o que torna o assentamento e seu sucesso essenciais para justificar suas reivindicações. O diálogo mantido, para esta e para pesquisas anteriores, deixa clara a formação consciente de obter terra própria para seu cultivo.

Nesse sentido manifesta-se, também, o escrito de Brito et al (2017) que trata do capital social no desenvolvimento do Itamarati II e apresenta resultados em que todos os agricultores entrevistados revelam possuir "um sentimento de identificação e pertencimento com a vida no campo. [...] A Cooperai é um indutor para o desenvolvimento no local e, também, uma ferramenta efetiva e unificadora nos âmbitos social, instrutivo e econômico". A categoria de análise é um instrumento, uma ferramenta, que não se justifica por si mesma, mas tem seu sentido no desenvolvimento das famílias assentadas. Indica a importância e a necessidade da cooperativa e, ao mesmo tempo, a sua insuficiência. 
A Cooperai foi instituída com o propósito de intermediar as atividades da lavoura e a compra dos produtos realizada por órgãos públicos e de encaminhar os alimentos à distribuição de variadas cestas básicas oferecidas pelo governo.

A família assentada no Itamarati II, instalada no seu eito, buscou meios para produzir e se voltou às agências governamentais para obter crédito, uma determinação comum nos assentamentos. Leite, Heredia e Medeiros (2004, p. 112) posicionaram-se a respeito do crédito: "Novas demandas se abrem que, agora, se voltam para as negociações com agentes de governos sobre a organização interna e para a obtenção de crédito e de infraestrutura".

Essa situação tornou impossível o rearranjo fundiário, em termos de reforma agrária, conforme informaram os depoentes cooperados. O domínio da comercialização, industrialização e exportação dos produtos, mantido e exercido pelas cooperativas modernas, subordinadas ao capital financeiro, foi descrito por Pochmann (2008): "A integração do agronegócio às cadeias de produção de commodities internacionais" e às operações comerciais em bolsa de valores, "são geralmente encaminhadas por grandes complexos empresariais" (2008, p. 75). Esta é a razão de ser da agroindústria.

Uma vez assentadas no Itamarati II, as famílias enfrentaram dificuldades em obter financiamentos e se defrontaram com as contradições sociais, manifestas no campo, definidas nos depoimentos como concentração da terra, do capital e da tecnologia. Elas reclamaram da impossibilidade de se capitalizarem para novos desenvolvimentos. A pesquisa de Rodrigues (2012, p. 42) também abordou o problema: "A dificuldade constatada desses empreendimentos em conseguir crédito é tida pelos próprios associados como o grande entrave para a realização de investimentos em novos maquinários e capacitação da mão-de-obra".

Do mesmo modo, Terra (2009) advertiu sobre a situação do Assentamento: "Apesar de o Assentamento Itamarati possuir mais de 1.800 famílias e ter viabilizado o acesso a recursos e serviços [...], tal transformação segue um círculo vicioso" Concluiu por uma "situação deplorável que se estabeleceu no assentamento", acentuando "a insuficiência da estrutura básica". O autor continuou sua análise nesses termos: "Se as condições das famílias do Assentamento Itamarati são difíceis, as das assentadas no Itamarati II são muito piores". O autor critica também as instituições que organizaram os assentamentos (MST, CUT e Fetagri) e o governo: todos falharam no processo de instalação "que vem se arrastando desde 2004" (TERRA, 2009, p. 305). Em outros termos, o desejo das instituições governamentais em promover a valorização da produção não se realizou na prática.

O ponto principal da discussão é a problemática da cooperativa, sem fins lucrativos, que faz a mediação entre agricultores e o Estado. No Itamarati II não opera uma cooperativa de compras e vendas, proposta por Singer, que industrializa, comercializa, financia a aluga maquinário. Ela somente faz a mediação entre o Estado comprador e o agricultor.

\section{A Função Social da Cooperai}

A entrevista com um cooperado forneceu a informação inicial para a análise da Cooperai: "No momento em que foi criada a cooperativa rural, nós, cooperados do Assentamento Fazenda Itamarati II, ganhamos força, poder e melhores condições para 
negociações e financiamentos". Outros depoimentos manifestaram que estava difícil cumprir a função social, qual seja, o comprometimento com a obtenção da terra própria e, principalmente, com uma produção compensatória. Alguns deles referiram-se ao reduzido financiamento concedido aos assentados. Os recursos escassos, constatados pela experiência de anos no trabalho agrícola, oportunizaram a crítica ao outro polo produtivo, aos grandes produtores que, mediante a ação de cooperativas das agroindústrias, modernas e capitalizadas, utilizam técnicas de administração, de competitividade, e praticam uma gestão de alta competência para criar, comercializar, industrializar e exportar os produtos agrícolas, mas que se despreocupam com o meio ambiente.

As atividades nos assentamentos são geridas por uma cooperativa singular, que exerce a função de "amparar a produção do pequeno proprietário assentado, sem fins lucrativos" (CONESULNEWS, 2016). A formação do Assentamento envolveu fatores múltiplos que abrangeram as famílias e seu movimento de luta: o governo federal (Incra), o governo estadual (Agraer), o município de Ponta Porã e sua área envolvida no processo de planejamento ambiental, econômico e social. Conforme observação in loco, a Cooperai, que organiza todas as atividades, não dispõe de sede própria e funciona precariamente em um salão com uma instalação comprometida. Foi criada em 2009 e recebeu apoio das incubadoras de cooperativas da Universidade Federal de Mato Grosso do Sul - UFMS.

Uma pequena trajetória histórica das cooperativas brasileiras de crédito auxilia no entendimento das ações da Cooperai e da função social que pretende cumprir.

Algumas cooperativas surgiram em vários lugares do Brasil. O padre suíço Theodor Amstadt, no Rio Grande do Sul, em 1902, as instalou nas regiões de imigrantes de origem alemã que tinham experiência com a cultura do trabalho associativo e, também, com atividades familiares comunitárias. Elas foram muito úteis e produtivas durante as décadas seguintes.

Nos primeiros anos do regime militar, no entanto, a legislação criou as diretrizes para um cooperativismo moderno que se organizou com estruturas tecnológicas de comercialização e de industrialização, viabilizadas pelo capital financeiro. A instituição da Lei n. 4.595, de 31 de dezembro de 1964, favoreceu a modernização, porque dispôs as cooperativas unidas às instituições financeiras. Ao Banco Central foram outorgados poderes para gerenciar o funcionamento das cooperativas.

As cooperativas prestamistas, de crédito ou singulares, criadas no começo do século 20, tiveram suas atividades creditórias fragilizadas pela Resolução n. 11/1965 do Banco Central. De acordo com as leis, foi criada a Organização das Cooperativas Brasileiras (OCB) em 2 de dezembro de 1969, durante o IV Congresso Brasileiro de Cooperativismo, que subsumiu o cooperativismo às políticas do Estado, interferiu e financiou a produção, a comercialização, a industrialização e a exportação dos produtos agrícolas.

A Resolução do Banco Central foi aperfeiçoada, em 1992, pela Resolução n. 1914 (<http://www.bcb.gov.br/pre/normativos/res/1992/pdf>), de acordo com a Constituição Federal Brasileira (1988). Os constituintes retomaram a legislação sobre as cooperativas singulares que, desde 1965, estavam impossibilitadas de subsistir, e as atualizaram. Em consequência, foram criadas, entre outras, também as cooperativas específicas, como as instaladas nos assentamentos, com objetivos dirigidos aos pequenos proprietários rurais. Elas se configuraram como uma estratégia de proteção aos trabalhado- 
res contra as adversidades historicamente vivenciadas pela pequena produção rural. A Constituição atribuiu à cooperativa a forma de administrar a escassez e enfrentar a pobreza com recursos, mas "a quantidade de terra e os créditos recebidos do Estado para produzir são, individualmente, insuficientes" (SCOPINHO, 2007, p. 87).

O cooperativismo exigiu uma rede de cooperação e trabalho coletivo, a fim de que fossem harmonizados os setores de desenvolvimento. Conforme descreve Scopinho (2007, p. 85), "A autonomia e a retomada das tradicionais formas de organização do trabalho são baseadas na cooperação espontânea, porque, de fato, cooperar é imprescindível para a sobrevivência desses trabalhadores".

No Assentamento Itamarati II a mediação da Cooperai definiu a produção em conjunto e os cooperados receberam treinamento e qualificação com os técnicos do Ministério da Agricultura, Pecuária e Abastecimento - Mapa. Houve pequeno financiamento para as atividades da lavoura, demonstrado nas entrevistas e nos sites governamentais e definido como "serviços rurais agropecuários e não agropecuários desenvolvidos em estabelecimento rural ou em áreas comunitárias próximas" (<www.bcb.gov.br/pre/bc_ atende/port/rural.asp>).

As lutas travadas pelos assentados correspondem integralmente a seus objetivos de reocupar e reorganizar a exploração da terra. Isso significa "elevar o assentado ao exercício dos direitos de cidadania. Tais movimentos lutam pela terra como expressão do trabalho e da vida, em contraposição ao movimento de expropriação determinado pelo capital" (BELLÉ; ALVES; SOUZA, 2013). Para cumprir os objetivos, foi organizada a Cooperai. A sua função específica foi mediar os produtos agrícolas com o mercado. Isso só foi possível pelo desempenho e intervenção do Estado.

\section{O Papel do Estado e a Mediação da Cooperativa}

A lógica do desenvolvimento capitalista remete o estudo para a incessante ampliação do capital constante e ao aumento das forças produtivas. O Estado, ao permitir à cooperativa mediar o financiamento, com a finalidade de operar no mercado um bom volume de mercadorias, de expandir a escala de produção e de garantir a distribuição, é reputado como protecionista.

O discurso dos assentados vai ao encontro dos desejos de dar condições para meIhorar sua renda. Com trabalho cooperativo, os assentamentos mantêm-se menos dependentes dos governantes, na visão de Costa et al. (2002, p. 26). A cooperativa, no entanto, ao operar apenas as intenções e os financiamentos do Estado, à margem da concorrência, torna o assentado ainda mais dependente do governo. A autonomia apenas esteve presente no foco inicial das famílias produtoras, determinando, conforme exposição de um cooperado, um rearranjo produtivo para os cooperados, com "a orientação de produtos hortifrutigranjeiros". Ao pequeno produtor rural cabe, geralmente, a produção de alimentos, mas ele tem reduzido acesso às tecnologias, tendo de, criativamente, buscá-las mais baratas para o cultivo.

As Escolas Família Agrícola de Ensino Médio, de Maracaju e de Itaquiraí, favorecem em muito o conhecimento tecnológico aos filhos de assentados do Itamarati II. O ensino de planejamento, gestão e de tecnologias nessas escolas, viáveis de serem executados na pequena propriedade e no assentamento rural, inclui um criativo conhe- 
cimento concreto e detalhado das condições que cercam o imóvel rural. Importante, também, é a participação das forças sociais na organização do ensino e do aprendizado realizados nas Escolas Família Agrícola (CARDOSO; HOFF, 2015).

O governo firma a política ambiental, econômica e social como opção da agricultura familiar e "como forma social de uso da terra que melhor responde à noção de sustentabilidade adequada às necessidades locais, regionais e do país" (RIBAS, 2003). Em tempos atuais, ainda é válido o que foi confirmado por estudos feitos por pesquisadores. Assim, Almeida considera que, mesmo com financiamentos, auxílio da cooperativa e conhecimentos produzidos nas escolas e nos ambientes não formais, "o sucesso das iniciativas atuais por um novo e diferente modo de desenvolvimento ainda está na razão direta dos resultados obtidos" (ALMEIDA, 1997).

A organização do Assentamento, complexa e sistêmica por envolver diferentes parceiros responsáveis pelos empreendimentos, baseou-se em estratégias, geridas pela Cooperai, com vistas a possibilitar o que Abramovay (2000, p. 9) define como "desenvolvimento regional sustentável e a dinâmica processual do ponto de vista da coesão social". Esse pensamento é reforçado por Iwasita (2001, p. 3) quando afirma que a cooperativa "não só representa o direito de defender os próprios interesses, como também, pode apontar soluções para os problemas e detectar oportunidades". Pela pesquisa realizada com um grupo pequeno no Itamarati II depreendeu-se que a Cooperai foi relativamente atuante e eficiente, porque teve a assistência dos órgãos governamentais.

O Estado propôs objetivos à produção no Assentamento: responsabilidade de viabilizá-lo, financiamento da produção por meio da cooperativa e a comercialização ao comprar o excedente para abastecer as bolsas de assistência social sustentadas pelo governo. Na prática do Itamarati II houve o comprometimento que possibilitou o que Leite, Heredia e Medeiros (2004, p. 65) denominaram "assegurar condições ao assentado para que produza dentro dos limites propostos"

Numa análise de comparações feita entre os objetivos do governo propostos e os resultados finais alcançados pelos cooperados, concluiu-se que os trabalhadores do assentamento nem sempre foram beneficiados pelas propostas governamentais. $\mathrm{O}$ sucesso das políticas não depende dos desejos humanos, principalmente quando eles são concretizados por instâncias extremamente burocráticas.

\section{Os Caminhos Percorridos pelos Produtos Gerados no Assentamento e o Destino do Consumo Final}

Os caminhos que o produto agrícola palmilha até o consumo final são motivo de insatisfação dos cooperados, fato atribuído à burocracia governamental, uma razão de reclamação dos produtores associados.

As mercadorias foram adquiridas pelo Programa de Aquisição Alimentar - PAA que as vendeu à Companhia Nacional de Abastecimento - Conab. Ambos são órgãos do Ministério de Agricultura, Pecuária e Abastecimento - Mapa. Dali, os alimentos foram repassados à prefeitura, por meio de um contrato com o Banco de Alimentos Municipal, com a incumbência de distribuí-los às famílias que pertencem ao grupo de vulnerabilidade alimentar, conforme o entendimento de uma entrevistada, confirmado pelo site da Conab: 
A atuação da Companhia contribui com a decisão do agricultor na hora de plantar, colher e armazenar e segue até a distribuição do produto no mercado, fase em que a garantia dos preços mínimos oferecidos pelo governo é traduzida em abundância no abastecimento e estímulo à produção. As operações realizadas pela Conab são coordenadas pelo Ministério da Agricultura, Pecuária e Abastecimento (COMPANHIA..., 2015).

Dessa forma, "os assentados têm em tese uma relação privilegiada com o Estado e estão sob sua gestão". As condições internas de cada lote de terra necessitaram do apoio governamental e diversos outros elementos da infraestrutura foram "indispensáveis à produção e à sobrevivência das famílias na área e, em grande medida, dependem diretamente do Estado". (LEITE, HEREDIA, MEDEIROS, 2004). As famílias dos cooperados vincularam-se às instituições governamentais, como o Incra, as prefeituras, Secretarias da Agricultura estaduais e municipais, organismos de assistência técnica, Instituto do Meio Ambiente e dos Recursos Naturais Renováveis - Ibama - e das Organizações Não Governamentais, como sindicatos, movimentos de luta, Federação de Trabalhadores, Contag e MST. Em resumo, todos esses órgãos centralizaram seus afazeres na Cooperai, que cumpriu o papel de mediadora social e econômica entre a produção e a comercialização dos produtos agrícolas.

No processo burocrático da distribuição entrou um novo órgão governamental: o Programa Nacional de Alimentação Escolar - Pnae - que informou o número de alunos cadastrados na Secretaria de Educação e o repassou para a prefeitura com a finalidade de aquisição dos alimentos na cooperativa, habilitada e credenciada junto a Conab. Três cooperados entrevistados afirmaram o que se pode resumir: os procedimentos governamentais para a compra de produtos agrícolas foram muito eficientes e, apesar da burocracia, favoreceram o cultivo nos assentamentos.

A Cooperai, na condição de mediadora entre essas várias instituições governamentais, exerceu a função de repartição centralizada, ao redor da qual girou o mundo social das famílias e por meio da qual se explicitou a organização produtiva. Foi por seu intermédio que se realizaram mudanças, reconhecidas pelos assentados, na produção e na comercialização das mercadorias do Itamarati II. Pessoas entrevistadas depuseram que a cooperativa realizou com eficiência a intermediação das ações e da função, a fim de que os alimentos chegassem à Secretaria da Educação. A Cooperai foi credenciada e habilitada junto a Conab com essa finalidade de mediar a produção de alimentos e de fazer a comercialização com o Programa de Aquisição Alimentar - PAA - e com o Programa Nacional de Alimentação Escolar - Pnae.

A mercadoria, ao chegar à mesa das escolas, foi precedida pela elaboração do cardápio e da pauta de compras realizada pelo nutricionista, responsável técnico do Pnae no âmbito municipal ou estadual. Ao encaminhamento antecederam-se, ainda, os princípios constitucionais atinentes à administração pública, insculpidos no artigo 37 da Constituição Federal de 1988 e na Lei n. 8.666 de 21 de junho de 1993, que regem os processos licitatórios. Definido estava também, que, do total dos recursos do Pnae repassados às entidades executoras, $30 \%$ deveriam ser utilizados na aquisição dos gêneros alimentícios, priorizando a produção oriunda dos assentamentos, mediada pela cooperativa. A aquisição, em alguns casos, pôde ser realizada, dispensando-se o proce- 
dimento licitatório, desde que os preços fossem compativeis com o mercado local. É o que determina o Fundo Nacional de Desenvolvimento da Educação, responsável pelo repasse do dinheiro:

Entre os órgãos governamentais encontra-se o Fundo Nacional de Desenvolvimento da Educação (FNDE), uma autarquia criada pelo Governo Federal pela Lei no 5.537, de 21 de novembro de 1968, cuja função é executar as políticas educacionais do Ministério da Educação e Cultura (MEC). Ele repassou os valores em dinheiro para a finalidade de efetuar compras solicitadas pelos projetos e programas em execução, ou seja: Pnae, Livro Didático, Dinheiro Direto na Escola, Biblioteca da Escola, Transporte Escolar, Caminho da Escola, Reestruturação e Aquisição de Equipamentos para a Rede Escolar Pública de Educação Infantil (BRASIL, 2015).

Em 2013 o Fundo Nacional de Desenvolvimento da Educação-FNDE (BRASIL, 2015) repassou à Secretaria Municipal de Educação de Ponta Porã, MS, o valor de R\$ 993.668,00 para fins de aquisição de alimentos destinados à merenda escolar, adquiridos diretamente da agricultura familiar, especificamente com a mediação da Cooperai. Deste valor, uma parcela de 30\% (R\$361.750,00) estava designada para a compra de merenda escolar. Conforme levantamento feito, a Secretaria Municipal gastou, neste item, apenas $\mathrm{R} \$ 280.100,46$ em 2013. Como não alcançou a meta de $30 \%$, estabelecida pelo FNDE, a quantia restante foi encaminhada para outro setor da educação, conforme critérios de compras estabelecidos pelo FNDE. Oitenta e um mil reais não foram gastos em compras de alimentos produzidos pelas famílias assentadas. Esse valor foi destinado

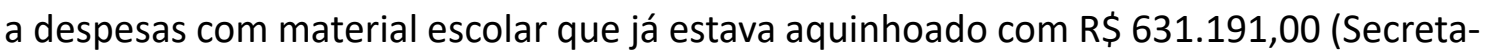
ria Municipal de Educação de Ponta Porã, novembro de 2013).

No ano de 2014 o FNDE repassou R\$ 404.250,00 à Secretaria Municipal de Educação com a finalidade de aquisição de alimentos para a merenda escolar. $O$ repasse para os itens compra de material escolar, equipamentos e de alimentos foi de $\mathrm{R} \$$ 1.117.372,00 no mesmo ano. Desse total, os 30\% destinados à aquisição de alimentos junto a cooperativa não foi feito pelo segundo ano consecutivo (Secretaria Municipal de Educação de Ponta Porã, novembro de 2014), o equivalentes a $\mathrm{R} \$ 140.557,00$. Consequentemente, houve aumento de verba para material escolar, conforme informação do setor, de $\mathrm{R} \$ 713.122 .00$ para $\mathrm{R} \$ 853.659,00$.

Em 2015 o FNDE repassou para a Secretaria Municipal de Educação de Ponta Porã um valor menor do que no ano anterior, ou seja, de $\mathrm{R} \$ 1.042 .938,00$. O gasto nas compras foi consumado junto a cooperativa. A Secretaria, nesse ano, alcançou a meta estabelecida pelo FNDE de 30\%, no valor de R\$346.899,97 e, assim, corrigiu a distorção anterior (Secretaria Municipal de Educação de Ponta Porã, novembro de 2015).

Para que o FNDE pudesse comprar os alimentos da cooperativa, os cooperados foram credenciados no Programa Nacional de Fortalecimento da Agricultura Familiar - Pronaf (<www.brasil.gov.br/economia-e-emprego/2015>). Uma vez habilitados, pela Declaração de Aptidão - DAF - junto ao Pronaf, participaram dos projetos sociais do governo federal. As organizações de agricultores apresentaram o Documento Especial de Pessoa Jurídica, conforme depoimento de vários entrevistados, que credenciou os cooperados, os representantes da cooperativa e os parceiros envolvidos, como a pre- 
feitura, a fim de que pudessem cumprir as funções de acompanhamento, logística de transporte, atendimento da qualidade, responsabilidade e distribuição dos alimentos às entidades.

A assistência técnica, o auxílio na elaboração de projetos e a emissão de Documento Auxiliar de Prestação de Serviço - Daps - couberam ao Agraer, um órgão de auxílio aos pequenos produtores rurais. $O$ gestor do Banco de Alimentos informou em entrevista que a fiscalização, a deliberação, o controle e o acompanhamento no desenvolvimento dos projetos foram realizados pela agente do Conselho Municipal de Assistência Social e, também, pela Conab de Campo Grande.

A Cooperai patrocinou o treinamento realizado pelos técnicos do PAA em 2013, que qualificou 20 cooperados, aptos para integrar o programa do governo federal, bastando apresentar a Declaração de Aptidão ao Pronaf para participar da qualificação. $O$ Programa existe há 12 anos e há 2 começou a ser instituído no Assentamento Itamarati II, em Mato Grosso do Sul.

As doações do governo foram controladas e registradas em documentação encaminhada para a Conab pelo Banco Municipal de Alimentos, expedindo-se, ao final do mês, um Termo de Recebimento e Aceite. A Conab liberou nota fiscal de pagamento para a Cooperai, sendo o repasse financeiro realizado posteriormente a cada produtor (COMPANHIA..., 2009, p. 128). O repasse feito pelo FNDE, conforme depoimentos de entrevistados e de representantes da Cooperai, teve um limite de valor monetário preestabelecido de no máximo de $\mathrm{R} \$ \mathbf{8}$. 000,00 para cada produtor, o que, conforme eles, "não correspondeu à expectativa". A reclamação foi a mesma que verificaram, também, Andrade et al. (2010): "As informações obtidas através dos questionários sobre a renda declarada se mostraram em muitos casos inferiores à realidade".

Os depoimentos com famílias assentadas do Itamarati II, como também os dados fornecidos por trabalhadores de outros assentamentos, como o de Itaquiraí, às margens do Rio Paraná, entrevistados anteriormente a esta pesquisa, deixaram bem clara a ideia de não quererem apenas sobreviver, mas gerar rendas acumulativas. Por isso, em Itaquiraí inovaram com produção de leite, criação de frangos de dois dias, serviços assalariados, como tratorista e motorista, entre outros.

Dois agricultores da Itamarati II destacaram que os cooperados tiveram de enfrentar a burocracia de diversos órgãos governamentais e municipais e de instituições não governamentais. Julgaram, porém, proveitosa a presença da Cooperai e de todas as siglas que entraram nos procedimentos.

As conclusões de Neves, Mussury e Mussury (2012) foram do seguinte teor: "Apesar de várias citações mencionando que a reforma agrária não está surtindo resultados, pode-se afirmar com certeza que a agroecologia, paralela à agregação de valor aos produtos oriundos da agricultura familiar, contribui fortemente para desmistificar essas indagações". Com os dados coletados e verificados nesta pesquisa na Itamarati II, entendeu-se que a intervenção direta do governo federal proporcionou apenas uma relativa viabilidade da agricultura familiar no assentamento. A essa conclusão também chegaram Toniasso et al. (2008) e Lima et al. (2016), a partir de suas pesquisas: os assentados atingiram apenas o mínimo de sustentabilidade. 
O governo federal, por intermédio de seus programas sociais de assistência Pnae e PAA (<www.fnde.gov.br/programas/alimentacao-escolar >), efetuados pela Conab em assentamentos rurais, cumpriu seu papel de gerador de produção e de renda para os assentados por meio de contratos de trabalho. Ao mesmo tempo, porém, limitou o valor máximo a $\mathrm{R} \$ 8.000,00$ para cada cooperado anualmente, em 2016, o que não correspondeu à renda real. A dependência das famílias dos programas sociais impossibilitou-as de estabelecer uma lavoura mecanizada e produtiva.

Os cooperados entrevistados afirmaram o que se pode resumir: os procedimentos governamentais para a compra de produtos agrícolas são eficientes e, apesar da burocracia, favoreceram o cultivo nos assentamentos. Destacaram, ainda, que os governos desempenham papel preponderante na sobrevivência do produtor assentado, mas acentuaram que se trata de uma renda apenas de sobrevivência.

O Estado financiou e dispôs à cooperativa para operar no mercado um bom volume de mercadorias e para expandir a escala de produção, e o que é importante, garantir a distribuição, um protecionismo, no entendimento do mercado. A função social do Estado seria dar condições para melhorar a renda obtida pelos assentados e ser um campo fértil para o capital se reproduzir mínima, mas constantemente. A mínima acumulação de capital não ocorreu e a concorrência foi suprimida pela mediação da cooperativa. Isso é difícil acontecer, diante do reduzido valor da mercadoria, inclusive de sua própria mercadoria que é a sua força de trabalho, somente obtido com a mediação protecionista da cooperativa como política pública do Estado.

A proposta da política pública somente se cumpriu, em parte, no resultado final. Isso tem sua razão de ser, porque o desenvolvimento econômico orienta-se pelas leis do modo de produção capitalista e não pelos desejos e propósitos humanos. O Estado, com a mediação da Cooperai, apesar dos desejos contidos na proposição de seus objetivos, não promoveu o assentado para a consecução de uma mínima acumulação de capital, como fez com os grandes produtores. Entende-se neste estudo que os objetivos desejados não são possíveis de serem alcançados. Isso porque "a tendência do desenvolvimento econômico atende às exigências das leis do modo de produção e não dos desejos humanos" (AUED, 1981, p. 25). A lógica do capital não se adequa a manifestações subjetivas transformadas em propostas governamentais, porque as leis capitalistas não dependem da vontade ou do desejo humano. Ela impõe ao proprietário da terra, incluído o produtor familiar, um comportamento de produzir e reproduzir constantemente o valor mediante seu trabalho, a fim de poder reproduzir-se como proprietário.

Trata-se de uma perspectiva teórica, sempre comprovada quando se mensuram as lacunas que surgem entre as intenções subjetivas dos planejadores e os resultados obtidos.

O número de participantes dos assentados na Cooperai é mínimo e os cooperados têm dificuldades de obter mais inscritos. Conforme seus dirigentes, "é difícil a missão de convencer as famílias para participarem", porque tudo "deve começar com treinamentos pelo PAA, a fim de torná-las aptas a produzir e participar dos programas federais". 
Em entrevista, um dirigente sindical denuncia a falta de interesse dos próprios assentados: "Encontram-se famílias que não se qualificam e não se comprometem com a agricultura familiar". Estende a crítica àquelas pessoas que não são "nativas das atividades agrícolas, não têm gana de produzir para sobreviver e estão nos assentamentos para comercializar a terra". Finaliza a entrevista afirmando que "os poucos, que são da lida e querem vencer, comprometem-se com a cooperativa e com os governos a fim de produzir seu sustento". O comprometimento de 1.700 famílias foi frágil, pois somente 20 aderiram à cooperativa. Quase uma dezena de siglas de órgãos governamentais entrou no jogo para acolher 20 titulares cooperados. Os dirigentes da cooperativa procuraram incentivar a cooperação, regularizar sua situação e participar dos programas. Concluíram: um árduo trabalho de conscientização leva tempo e demanda paciência.

O FNDE liberou verbas para o município seguindo os mesmos critérios que adota para todos os municípios brasileiros como valor monetário por aluno matriculado. Estabeleceu, em Ponta Porã, que o dinheiro devesse ser gasto de acordo com suas normas. Como isso não aconteceu em 2013 e 2014, a verba foi reprogramada para o setor de aquisição de materiais, produtos ou equipamentos, e essa reprogramação não se repetiu porque o governo federal diminuiu a cota para o ano seguinte, uma pena aplicada com a finalidade de forçar os municípios a seguirem a regulamentação. Diminuir os valores para a compra de alimentos dos assentados, como ocorreu em 2015, afetou diretamente a quantidade de produção.

Conforme seus registros, a Cooperai procurou utilizar os programas do governo e fomentar a produtividade e a renda, desempenhando seu papel de mediador entre 0 governo e os produtores. Os resultados apontaram para um pequeno número de unidades de irrigação na lavoura; reduzido acesso ao financiamento e, consequentemente, às tecnologias de produção e proteção econômica do governo na aquisição dos gêneros alimentícios diretamente da agricultura familiar.

Os dois programas, PAA e Pnae, representaram para os assentados uma renda anual, entretanto foi apenas uma renda de sobrevivência familiar, conseguida graças à mediação da cooperativa. O mercado dos assentados não subsistiria sem os órgãos governamentais. $\mathrm{E}$, ainda, há pouca esperança de que a renda mínima possa propiciar uma lavoura mecanizada e produtiva. Mais difícil torna-se a situação do cooperado, porque a Cooperai, segundo seus dirigentes, dirige suas ações "sem fins lucrativos".

A atuação das cooperativas singulares foi avaliada por alguns artigos de periódicos como tendo o papel de diminuição da dependência do Estado. No caso deste estudo, a realização da função social da Cooperai está totalmente adstrita às instituições governamentais.

O Estado, com a mediação da Cooperai, não promoveu o assentado para a consecução de uma acumulação de capital, a despeito dos desejos propostos nos objetivos governamentais. Entende-se a razão do hiato constatado entre o proposto e o obtido, porque o desenvolvimento econômico depende das leis mercadológicas e do mercado financeiro, que é alheio à vontade do produtor. É a conclusão que se chega a partir da teoria da produção capitalista, sempre comprovada quando se mensuram as intenções propostas pelos governos que se ausentam nos resultados finais. A mesma problemática foi revelada por Terra (2009, p. 111): 
Para os empresários rurais e agroindustriais, um assentamento modelo é aquele que realiza parcerias com o agronegócio. Já para os assentados, essa parceria representa a completa submissão das famílias, quer trabalhando como mão de obra barata, quer, sobretudo, entregando seus lotes em arrendamento para o cultivo da soja, do milho e de outros produtos de interesse das grandes empresas

As razões de ser do mercado apresentaram a contradição existente entre a produção e a venda dos produtos, realizadas pelos assentados, de um lado, e a agroindústria, de outro. A contradição que se estabeleceu na luta dos assentados contra o agronegócio, no caso específico deste estudo, manifestou-se pela "solução" do Estado comprador que, com a mediação da cooperativa, descapitalizada e sem forças no mercado competitivo, resultou em protecionismo, sem nenhuma competição, sem concorrência, esta já ultrapassada pela fase imperialista da produção material.

\section{CONSIDERAÇÕES FINAIS}

Conforme seus registros, a Cooperai procurou utilizar os programas do governo e fomentar a produtividade e a renda, desempenhando seu papel de mediador entre o governo e os produtores. Os resultados apontaram para um pequeno número de unidades de irrigação na lavoura; reduzido acesso ao financiamento e, consequentemente, às tecnologias de produção, e proteção econômica do governo na aquisição dos gêneros alimentícios diretamente da agricultura familiar.

As contradições sociais são apreendidas como o domínio da comercialização, industrialização e exportação dos produtos, obtido pelas cooperativas modernas aliadas ao capital financeiro, que submete a agricultura a seus interesses, conforme argumenta Pochmann (2008, p. 75): "A integração do agronegócio às cadeias de produção de commodities internacionais" e às operações comerciais em bolsa de valores, "são geralmente encaminhadas por grandes complexos empresariais". Essa situação dificulta a produção familiar, acrescentaram os depoentes cooperados do Itamarati II.

Os agricultores entrevistados possuem um sentimento de identificação com a vida no campo e revelaram características importantes, como reocupar e reorganizar a exploração da terra. Lutam pela terra como expressão do trabalho e da vida, em contraposição ao movimento de expropriação determinado pelo capital. Com a mediação da Cooperai houve uma melhor remuneração pelo produto, mas não há presença de comercialização, industrialização, projetos de financiamento e aluguel de máquinas agrícolas.

Esta pesquisa pontual pode colaborar com os estudos acadêmicos no intuito de um entendimento geral sobre a produção das famílias assentadas. A singularidade dos objetos deste estudo tem a ver com a universalidade do modo de produzir na sociedade atual, porque a singularidade de cada local investigado manifesta necessariamente características do universal que é a produção mundial.

Os tipos de produção - da agroindústria e do Assentamento - foram apreendidos pelas razões de ser do mercado que o levaram a não patrocinar a agricultura dos cooperados no Assentamento: exatamente porque esta não se subordina a seus interesses. A análise ligou a produção material dos cooperados aos condicionantes econômicos das relações capitalistas. A função social que o Assentamento assumiu é diversa das diretrizes do capital. 
A livre-concorrência não é exercitada ou é impossibilitada de se efetivar porque, no caso da cooperativa do Itamarati II, sua mediação mantém-se colada a órgãos do governo que propiciam o protecionismo nos plantios e na comercialização dos produtos. Não há exercício da concorrência, enquanto o agronegócio já ultrapassou a fase concorrencial, ligado que se encontra com o capital financeiro e com as commodities internacionais.

Evidentemente, este estudo não traz um conhecimento pelo qual se possa estender a todas as cooperativas. Vimos que há diversas experiências e diferenciados resultados, comunicados em congressos científicos. Neste trabalho considerou-se a Cooperai um caso específico de uma cooperativa que exerce a mediação do produto dos trabaIhadores assentados nos negócios de compra e venda que, entretanto, torna o assentado ainda mais dependente do Estado. É uma singularidade investigada que manifesta um caminho diverso da sociedade produtora da sociedade e apresenta uma fisionomia que possui traços fundamentais conferidos pela universalidade da produção mundial.

\section{REFERÊNCIAS}

ABRAMOVAY, R. O capital social dos territórios: repensando o desenvolvimento rural. Economia Aplicada. São Paulo, vol. IV, n. 2, p. 379-397, abr./jun. 2000.

ALMEIDA, J. A problemática do desenvolvimento sustentável. In: BECKER, D. F. (Org.). Desenvolvimento sustentável: necessidade e/ou possibilidade. Santa Cruz do Sul: Edunisc, 1997.

AGÊNCIA DE DESENVOLVIMENTO AGRÁRIO E EXTENSÃO RURAL (Agraer); SECRETARIA DE ESTADO DE PRODUÇÃO E AGRICULTURA FAMILIAR (Sepaf). Agricultores Familiares - MS. Campo Grande, jun. 2015.

ANDRADE, E. S. et al. A crise do sistema sócio-proprietário de produção nas unidades I e II do Assentamento Itamarati em Ponta Porã/MS. Sociedade Brasileira de Economia, Administração e Sociologia Rural, Campo Grande, MS, n. 48, p. 2428 jul. 2010.

AUED, I. M. Ensaio sobre a Lei Geral da Acumulação Capitalista. Revista Unimar. Maringá: UEM, v. 3, n. 1, p. 21-36, set. 1981.

BELLÉ, F. L; ALVES, G. L; SOUZA, C. C de. Impactos sobre o desenvolvimento regional decorrentes do Assentamento Itamarati. Ponta Porã (MS): Campo Grande: Albuquerque: Revista de História, v. 5, n. 9, p. 9-33, jan./jun. 2013.

BORGES, J. L. MST: do Produtivismo a Agroecologia Política. Disponível em: Disponíel em: <www.humanas.ufpr.br/evento/Sociologia>. Acesso em: set. 2018

BRASIL. Constituição da República Federativa do Brasil. 1988.

Fundo Nacional de Desenvolvimento da Educação - FNDE. Alimentação escolar - repasses financeiros. Disponível em: <http://www.fnde.gov.br/programas/alimentacao-escola>. Acesso em: 13 dez. 2015.

Fundo Nacional de Desenvolvimento da Educação - NDE. Perguntas Frequentes. Disponível em: <http://www.fnde.gov.br/acesso-a-onformacao/institucional/perguntas-frequentes-institucional-2/perguntas-frequentes-geral >. Acesso em: 13 dez. 2017.

BRITO, A. R. et al. Capital Social e Desenvolvimento Endógeno no Assentamento Itamarati II em Ponta Porã. SEMINÁRIO INTERNACIONAL SOBRE DESENVOLVIMENTO REGIONAL, 8., 2017. Anais... Santa Cruz do Sul, 2017.

CARDOSO, M. A.; HOFF, S. A Organização do trabalho didático em duas escolas família agrícola sul-mato-grossenses. In: SOUZA, A. A. de; CENTENO, Carla V; LANCILLOTTI, S. S. P. Campo Grande: o trabalho didático em exame. Dourados: Editora UEMS, 2015. p. 133-152.

COMPANHIA NACIONAL DE ABASTECIMENTO. Conab. Agricultura e abastecimento alimentar: políticas públicas e mercado agrícola. Brasília: Conab, 2009.

30 nov. 2015.

Quem somos. Disponível em: <http://www.conab.gov.br/conab-quemSomos.php>. Acesso em:

CONESULNEWS. Famílias do Itamarati recebem apoio para comercializar produção. Maio 2016. Disponível em: <http://www.conesulnews.com.br/cidade/familias-do-itamarati-recebem-apoio-para-comercializar-producao>. Acesso em: 12 nov. 2017. 
COSTA, R. B. da et al. Alternativas agropastoris de produção sustentavel para agricultura familiar. Interações, Revista Internacional de Desenvolvimento Local, Campo Grande, v. 3, n. 5, p. 25-32, 2002.

IWASITA, A. R. Asentamientos Humanos y Desarrollo Local. Interações - Revista Internacional de Desenvolvimento Local, Campo Grande: UCDB, v. 1, n. 2, mar. 2001.

LEITE, S.; HEREDIA, B.; MEDEIROS, L. S. et al. Impactos dos assentamentos: um estudo sobre o meio rural brasileiro. São Paulo: Ed. Unesp; Nead; Incra; MDA, 2004.

LIMA, V. A. M. O. et al. Análise da eficiência de pequenas propriedades rurais através do método da Análise Envoltória de Dados (DEA). Informe Gepec (Impresso), v. 20, p. 58-70, 2016.

LUKACS, G. Marx e Engels como Historiadores da Literatura. São Paulo: Boitempo, 2016

MARCONI, I. C.; SANTOS, L. M. L. dos. Cooperativismo no MST: o caso da Copran. Revista Interações, Campo Grande, v. 17, n. 2, p. 173-183, abr./jun. 2016.

MARX, K. O Capital 1,2. Rio de Janeiro: Editora Civilização Brasileira, 1980.

NEVES, M. F.; MUSSURY, L. A; MUSSURY, R. M. Comunicação \& Mercado, Dourados: Unigran, vol. 1, n. 1, p. 85-103, jan./jul. 2012.

OLIVEIRA, R. D. de; SOUZA, C. C.; MERCANTE, M. A. Análise e diagnóstico da sustentabilidade do assentamento rural Eldorado II, no município de Sidrolândia (MS). Informe Gepec (on-line), v. 21, p. 149-168, 2017.

POCHMANN, M. O emprego na globalização. São Paulo: Boitempo, 2008.

RIBAS, M. M. P. Condicionantes de Desenvolvimento Local dos Assentamentos Rurais em Mato Grosso do Sul: o caso de Capão Bonito II, 2003. Dissertação (Mestrado em Desenvolvimento Local). Universidade Católica Dom Bosco - UCDB, Campo Grande - MS, 2003.

RODRIGUES, M. C. A Economia Solidária no Assentamento Itamarati. Londrina: Unopar, 2012.

SAVIANI, D. Competência política e compromisso técnico. Educação \& Sociedade, São Paulo: Cortez Ed. v. 15, p. 111-142, ago. 1983.

SCOPINHO, R. A. Sobre cooperação e cooperativas em assentamentos rurais. Psicologia \& Sociedade, São Carlos: Universidade Federal de São Carlos, Edição Especial 1, p. 84-94, 2007.

TERRA, Ademir. Reforma agrária por conveniência e/ou por pressão? Assentamento Itamarati em Ponta Porã, MS: “O Pivô da Questão. 2009. Dissertação (Mestrado) - Unesp, Presidente Prudente, 2009.

TONIASSO, H. R. et al. Agricultura familiar e associativismo rural - o caso Associação Harmonia de Agricultura Familiar de Mato Grosso do Sul e sua Sustentabilidade. Informe Gepec, Campo Grande, vol 11, n. 2, p. 1-10, 2008. 